\title{
Efficacy and tolerability of a combined gatifloxacin plus prednisolone formulation for topical prophylaxis after LASIK
}

This article was published in the following Dove Press journal:

Clinical Ophthalmology

15 February 2011

Number of times this article has been viewed

\author{
Mauro Campos \\ Cristina Muccioli \\ João BNS Malta \\ Rafael A Gerade \\ André LA Salame \\ Rubens Belfort Jr \\ Department of Ophthalmology, \\ Hospital São Paulo, Universidade \\ Federal de São Paulo, Brazil
}

Correspondence: Rubens Belfort Jr Hospital São Paulo - UNIFESP, Rua Dr Diogo de Faria, 1036 - 4o. andar, 04037-003, São Paulo, Brazil $\mathrm{Tel}+55$ I I 50844982

Fax +55 II 508। 7275

Email presidente@spdm.org.br
Purpose: To compare the efficacy and tolerability of a fixed-dose combination of $0.3 \%$ gatifloxacin and $1 \%$ prednisolone formulation versus the same agents administered separately for prophylaxis in a laser-assisted in situ keratomileusis (LASIK) population.

Methods: In a prospective, randomized, double-masked, parallel-group study, 97 patients were evaluated for signs and symptoms of ocular infection or inflammation after bilateral LASIK. Group 1 (50 patients, 100 eyes) received a combined formulation of $0.3 \%$ gatifloxacin $+1 \%$ prednisolone acetate $\left(\right.$ Zypred $\left.^{\circledR}\right)$ plus placebo. Group 2 (47 patients, 94 eyes) received conventional treatment with the same agents from separate vials. The cohorts were similar in age, sex, race, and refractive error. Baseline and postoperative assessments were made on surgery days $-2,1,3$, and 15 and consisted of visual acuity; intraocular pressure; severity of inflammation of eyelids, conjunctiva, and cornea; tearing; ocular discomfort (foreign-body sensation, itching, or photophobia); and ocular pain. The posterior segment was evaluated at the screening and exit visits.

Results: No ocular infection or persistent inflammation was detected in either group at any time. All objective and subjective criteria of efficacy were similar regardless of treatment, with no significant differences between the groups. More patients who were dosed with the combined agent complained of mild ocular discomfort on day 3, but this difference had disappeared by day 15 . Conclusion: Post-LASIK topical prophylaxis with combined gatifloxacin + prednisolone eye drops $\left(Z^{2 y p r e d}{ }^{\circledR}\right)$ was well tolerated. This formulation appears to be therapeutically equivalent to conventional dosing with gatifloxacin and prednisolone from individual bottles for topical prophylaxis after laser refractive surgery.

Keywords: gatifloxacin, prednisolone, LASIK, prophylaxis

\section{Introduction}

In addition to preservative-free moisturizing eye drops to be used ad lib, ${ }^{1,2}$ laser-assisted in situ keratomileusis (LASIK) patients are usually prescribed antibiotic and steroid eye drops for the first 5-14 days after surgery in order to prevent infection and minimize inflammation. ${ }^{3-7}$ Compliance with prophylactic medications is critical to reducing the risk of serious complications that can have a devastating effect on a person's quality of life.

Topical gatifloxacin $0.3 \%$ is a fourth-generation fluoroquinolone that has been shown to be useful in ocular surgical prophylaxis. ${ }^{7-10}$ Both in vivo and in vitro studies demonstrate improved potency of gatifloxacin against Gram-positive bacteria and similar or better potency against Gram-negative bacteria compared with thirdgeneration levofloxacin. ${ }^{11-13}$ A $1 \%$ prednisolone acetate suspension has been used for many years to control inflammation that can interfere with the healing process after ocular procedures. ${ }^{14}$ 
In a prospective, randomized, double-masked, parallel-group comparative study, we looked at the results of prophylactic administration with a fixed-dose combined formulation of $0.3 \%$ gatifloxacin $+1 \%$ prednisolone $\left(\right.$ Zypred $^{\circledR}$, Allergan, Irvine, CA, USA) versus conventional dosing with the separate agents after LASIK.

\section{Patients and methods}

Out of a total of 101 consecutive patients seeking LASIK correction at our university-affiliated outpatient clinic, 97 patients (194 eyes) met the protocol inclusion/exclusion criteria and were recruited for the study. These patients were randomly assigned by computer to one of two treatment groups. The group assignment was masked from patients as well as from investigators and clinic staff.

Group 1 consisted of 50 patients who received the combined $0.3 \%$ gatifloxacin $\left(\right.$ Zymar $^{\circledR}$, Allergan $)+1 \%$ prednisolone acetate eye drops (Pred Forte ${ }^{\circledR}$, Allergan) and placebo (inactive ingredients of the $0.3 \%$ gatifloxacin ophthalmic solution: edetate disodium, water, benzalkonium chloride, and sodium chloride). Group 2 consisted of 47 patients who received $0.3 \%$ gatifloxacin and $1 \%$ prednisolone acetate drops from separate vials. All patients received two identical bottles and were instructed to instill one drop from each bottle in each eye four times a day, with a 5-minute wait between drops, beginning on the day of surgery (day 0) until discharged from the study (day 15).

The enrollment criteria consisted of men and women of any race between 18 and 60 years of age, in good general health, and with either myopia of up to -8.0 diopters (D) or hyperopia of up to $+4.0 \mathrm{D}$, with or without astigmatism of up to $3.0 \mathrm{D}$, and whose dilated funduscopy at the time of enrollment was within normal limits. Patients were excluded from the study if they had i) a history or evidence of current intraocular hypertension; ii) a history or evidence of current systemic disease such as diabetes mellitus, autoimmune disorder, or herpetic, viral, bacterial, or fungal disease; iii) used steroids or nonsteroidal anti-inflammatory drugs within 14 days of enrollment; iv) had a history of ocular trauma or inflammatory disease; v) used ocular antimicrobial drugs within 30 days of enrollment; vi) participated in another clinical study within the 12 months prior to surgery; vii) had single-eye vision; viii) had decreased vision from lens opacities; or viiii) had known or suspected hypersensitivity to gatifloxacin, corticosteroids, or topical anesthetic agents. Pregnant or lactating women or women of childbearing age who were not using reliable birth control methods were also excluded. In addition, all women of childbearing age who used birth control had to have a negative pregnancy test before enrollment. This protocol was approved by the hospital review board. The surgical candidates were asked to stop wearing contact lenses for at least 2 weeks before the LASIK procedure and to read and sign informed consent forms.

All patients underwent simultaneous, bilateral, wavefrontguided LASIK by the same surgeon using the LADARVision ${ }^{\circledR}$ system (Alcon Laboratories, Inc., Hünenberg, Switzerland). Patients were evaluated 2 days before surgery (day -2) and on postoperative day 1,3 , and 15 for signs and symptoms of ocular inflammation or infection. Baseline values were obtained for visual acuity (VA), intraocular pressure (IOP), clinical signs of inflammation of eyelids and conjunctiva (hyperemia, edema, discharge, or crusting), corneal edema, and corneal staining. These assessments were repeated on subsequent clinic visits, at which time any adverse events were also recorded. A funduscopic examination was performed on entering and exiting the study. At each visit, patients' complaints of tearing, eye discomfort (foreign-body sensation, itching, or photophobia), and ocular pain were also collected and made part of the study record.

The VA was determined with an Early Treatment Diabetic Retinopathy Study (ETDRS) chart and expressed in logarithm of the minimum angle of resolution values. Postoperatively, the vision was measured uncorrected. The IOP readings were taken with the Goldmann applanation tonometer, and slit-lamp biomicroscopy and physician clinical impression were used to gather the observational data. The ocular pain scale ranged from $0=$ no pain to $5=$ severe pain as rated by the patients. The fundus was visualized with the ophthalmoscope.

The data were reported by number and percentage of eyes in each treatment group and analyzed at a 5\% confidence level $(P=0.05)$ with $\mathrm{SAS}^{\circledR} / \mathrm{STAT}^{\circledR}$ software (Version 9.1.3) (SAS Institute Inc., Cary, NC, USA) as follows: the Student's $t$-test was applied to age, VA, and IOP; the Chi-square test was applied to sex, race, and refractive error; the Mann-Whitney test was applied to the biomicroscopy data; and Fisher's exact test was used to analyze the patient-reported symptoms.

\section{Results}

The demographic profile of the 97 patients who participated in this study is detailed in Table 1. All evaluable patients (194 eyes) remained in the study through the day 15 exit visit. At randomization, the treatment groups were similar for age, sex, and race. Patients in the separate gatifloxacin and prednisolone group included three individuals identified as Asian. 
Table I Patient demographics by treatment group $(\mathrm{N}=97)$

\begin{tabular}{|c|c|c|c|}
\hline & $\begin{array}{l}\text { Group } I^{a} \\
\mathbf{n}=\mathbf{5 0} \\
\text { No. (\%) }\end{array}$ & $\begin{array}{l}\text { Group } 2^{b} \\
n=47 \\
\text { No. (\%) }\end{array}$ & $P$ \\
\hline Age (years) & & & 0.3821 \\
\hline Mean & 32.5 & 31.1 & \\
\hline Median & 30 & 29 & \\
\hline Sex & & & 0.8637 \\
\hline Male & $20(40)$ & I8 (38.3) & \\
\hline Female & $30(60)$ & $29(61.7)$ & \\
\hline Race & & & 0.0851 \\
\hline Caucasian & $46(92)$ & $42(89.4)$ & \\
\hline Mulatto & $4(8)$ & $2(4.3)$ & \\
\hline Asian & $0(0)$ & $3(6.4)$ & \\
\hline
\end{tabular}

Notes: aCombined treatment with gatifloxacin + prednisolone; ${ }^{\text {bSeparate treatment }}$ with gatifloxacin and prednisolone.

The distribution of refractive errors prompting LASIK correction was also similar between the groups (Table 2). There were more eyes with isolated myopia in Group 1 (combined treatment), and overall more eyes diagnosed with astigmatism in Group 2 (separate treatment), but Chi-square analysis showed that these differences were not statistically significant $(P=0.2318)$.

Bilateral wavefront-guided LASIK was performed uneventfully in 97 patients (194 eyes). There were no ensuing complications or other reported problems necessitating concurrent medications. The postoperative visual improvement (Table 3) was similar regardless of drug regimen. By day 1, all patients had gained at least one line on the ETDRS chart, and their visual acuity continued to improve until they were discharged from the study.

IOP remained stable in all patients throughout the early postoperative period encompassed by this study and was virtually identical regardless of which eye drops were given. The median IOP measurement was $12.0 \mathrm{~mm} \mathrm{Hg}$ in both groups on days 1, 3, and 15 (Table 4).

Postoperative biomicroscopy (Table 5) revealed no statistical differences between treatment groups when judged by objective parameters of inflammation. Eyelid hyperemia

Table 2 Indications for laser-assisted in situ keratomileusis by treatment group $(\mathrm{N}=194)$

\begin{tabular}{lll}
\hline Refractive diagnosis & $\begin{array}{l}\text { Group Ia } \\
\mathbf{n}=\mathbf{I 0 0} \\
\text { No. }(\%)\end{array}$ & $\begin{array}{l}\text { Group 2 } \\
\mathbf{n}=\mathbf{9 4} \\
\text { No. }(\%)\end{array}$ \\
\hline Myopia & $21(2 I)$ & $12(12.8)$ \\
Myopia + astigmatism & $66(66)$ & $72(76.6)$ \\
Hyperopia + astigmatism & $13(13)$ & $10(10.6)$ \\
\hline
\end{tabular}

Notes: ${ }^{a}$ Combined treatment with gatifloxacin + prednisolone; ${ }^{b}$ Separate treatment with gatifloxacin and prednisolone.
Table 3 Pre- and postoperative visual acuity (logarithm of the minimum angle of resolution) over time by treatment group $(\mathrm{N}=194)$

\begin{tabular}{llll}
\hline Day $^{\mathbf{a}}$ & $\begin{array}{l}\text { Group I } \\
\mathbf{n}=\mathbf{1 0 0}\end{array}$ & $\begin{array}{l}\text { Group 2 } \\
\mathbf{n}=\mathbf{9 4}\end{array}$ & $\mathbf{P}$ \\
\hline-2 & & & \\
$\quad \begin{array}{l}\text { Mean } \pm \text { SD } \\
\text { Median }\end{array}$ & $-0.06 \pm 0.10$ & $-0.04 \pm 0.09$ & \\
I & -0.10 & -0.06 & 0.2526 \\
$\quad$ Mean \pm SD & $-0.02 \pm 0.12$ & $-0.01 \pm 0.14$ & \\
$\quad$ Median & 0.0 & 0.0 & 0.6783 \\
$3 \quad$ & & & \\
$\quad$ Mean \pm SD & $-0.05 \pm 0.12$ & $-0.05 \pm 0.14$ & \\
$\quad$ Median & -0.05 & 0.0 & 0.955 I \\
I5 & & & \\
$\quad$ Mean \pm SD & $-0.04 \pm 0.11$ & $-0.04 \pm 0.13$ & \\
$\quad$ Median & -0.05 & -0.01 & 0.7336
\end{tabular}

Notes: aln relation to laser-assisted in situ keratomileusis; ${ }^{\mathrm{b} C o m b i n e d ~ t r e a t m e n t ~ w i t h ~}$ gatifloxacin + prednisolone; 'Separate treatment with gatifloxacin and prednisolone. Abbreviation: SD, standard deviation.

was recorded in one eye from Group 1 on days 1 and 3 and in none from Group 2. By day 15, hyperemia was recorded in four eyes from both groups. The lid edema data were identical regardless of treatment; edema was documented in one eye on day 3 and in two eyes on day 15 from either group. Eyelid crusting was recorded preoperatively in four eyes from Group 1 and two eyes from Group 2. It was still present on day 1 (two and two eyes), day 3 (one and two eyes), and day 15 (four and two eyes), respectively.

Slit-lamp assessment of the conjunctiva on day 1 showed mild hyperemia in seven eyes from Group 1 and in six eyes from Group 2. On day 3, mild hyperemia was recorded in eight and four eyes, respectively, and by day 15 it was documented

Table 4 Pre- and postoperative intraocular pressure $(\mathrm{mm} \mathrm{Hg})$ over time by treatment group $(\mathrm{N}=194)$

\begin{tabular}{llll}
\hline Day $^{\mathrm{a}}$ & $\begin{array}{l}\text { Group I } \\
\mathbf{n}=\mathbf{1 0 0}\end{array}$ & $\begin{array}{l}\text { Group 2 } \\
\mathbf{n}=\mathbf{9 4}\end{array}$ & $\mathbf{P}$ \\
\hline-2 & & & \\
$\begin{array}{l}\text { mean } \pm \text { SD } \\
\text { median }\end{array}$ & $13.5 \pm 2.2$ & $13.5 \pm 2.1$ & \\
$\mathrm{I}$ & 13.5 & 13.0 & $0.945 \mathrm{I}$ \\
$\begin{array}{l}\text { mean } \pm \text { SD } \\
\text { median }\end{array}$ & $12.2 \pm 2.0$ & $12.0 \pm 2.1$ & \\
$3 \begin{array}{l}\text { mean } \pm \text { SD } \\
\text { median }\end{array}$ & 12.0 & 12.0 & 0.3537 \\
$\begin{array}{l}\text { I5 } \\
\text { mean } \pm \text { SD }\end{array}$ & $12.3 \pm 1.8$ & $11.9 \pm 2.1$ & \\
median & $12.8 \pm 2.0$ & 12.0 & 0.1507 \\
\hline
\end{tabular}

Notes: aln relation to laser-assisted in situ keratomileusis; ${ }^{\mathrm{b} C o m b i n e d ~ t r e a t m e n t ~ w i t h ~}$ gatifloxacin + prednisolone; 'Separate treatment with gatifloxacin and prednisolone. Abbreviation: SD, standard deviation. 
Table 5 Signs of inflammation over time by treatment group $(\mathrm{N}=194)$

\begin{tabular}{|c|c|c|c|c|c|c|}
\hline \multirow[t]{2}{*}{$\begin{array}{l}\text { Biomicroscopy } \\
\text { findings }\end{array}$} & \multirow[t]{2}{*}{ Dayc } & \multicolumn{2}{|c|}{$\begin{array}{l}\text { Group } I^{a} \\
n=100\end{array}$} & \multicolumn{2}{|c|}{$\begin{array}{l}\text { Group } 2^{b} \\
n=94\end{array}$} & \multirow[t]{2}{*}{$P$} \\
\hline & & No. & $(\%)$ & No. & $(\%)$ & \\
\hline \multicolumn{7}{|l|}{ Eyelids } \\
\hline \multirow[t]{4}{*}{ Hyperemia } & -2 & 2 & $(2)$ & 0 & $(0)$ & 0.1692 \\
\hline & 1 & 1 & (I) & 0 & $(0)$ & 0.3323 \\
\hline & 3 & 1 & (I) & 0 & $(0)$ & 0.3323 \\
\hline & 15 & 4 & (4) & 4 & (4.3) & 0.9290 \\
\hline \multirow[t]{4}{*}{ Edema } & -2 & 2 & $(2)$ & 0 & $(0)$ & 0.1692 \\
\hline & 1 & 0 & $(0)$ & 0 & (0) & - \\
\hline & 3 & 1 & (I) & 1 & (I.I) & 0.9650 \\
\hline & 15 & 2 & $(2)$ & 2 & (2.I) & 0.9503 \\
\hline \multirow[t]{4}{*}{ Crusting } & -2 & 4 & (4) & 2 & (2.I) & 0.4527 \\
\hline & 1 & 2 & $(2)$ & 2 & (2.I) & 0.9503 \\
\hline & 3 & I & (I) & 2 & $(2.1)$ & 0.5257 \\
\hline & 15 & 4 & (4) & 2 & $(2.1)$ & 0.4527 \\
\hline \multicolumn{7}{|l|}{ Conjunctiva } \\
\hline \multirow[t]{4}{*}{ Hyperemia } & -2 & 0 & $(0)$ & 0 & $(0)$ & - \\
\hline & 1 & 7 & (7) & 6 & (6.4) & 0.8640 \\
\hline & 3 & 8 & (8) & 4 & (4.3) & 0.2805 \\
\hline & 15 & 2 & (2) & 2 & (2.I) & 0.9503 \\
\hline \multirow[t]{4}{*}{ Edema } & -2 & 0 & $(0)$ & 0 & $(0)$ & - \\
\hline & 1 & 0 & (0) & I & (I.I) & 0.3023 \\
\hline & 3 & 0 & $(0)$ & 0 & $(0)$ & - \\
\hline & 15 & 0 & (0) & 2 & (2.I) & 0.1436 \\
\hline \multicolumn{7}{|l|}{ Cornea } \\
\hline \multirow[t]{4}{*}{ Edema } & -2 & 0 & $(0)$ & 0 & $(0)$ & - \\
\hline & 1 & 2 & (2) & 0 & $(0)$ & 0.1692 \\
\hline & 3 & 1 & (I) & 0 & (0) & 0.3323 \\
\hline & 15 & 0 & (0) & 0 & (0) & - \\
\hline \multirow[t]{4}{*}{ Staining ${ }^{d}$} & -2 & 0 & (0) & 0 & (0) & - \\
\hline & 1 & 8 & (8) & 3 & (3.2) & 0.1489 \\
\hline & 3 & 6 & (6) & 9 & (9.6) & 0.3528 \\
\hline & 15 & 4 & (4) & 6 & (6.4) & 0.4543 \\
\hline
\end{tabular}

Notes: aCombined treatment with gatifloxacin + prednisolone; bSeparate treatment with gatifloxacin and prednisolone; In relation to laser-assisted in situ keratomileusis; ${ }^{d}$ Fluorescein staining was minimal in all positive cases.

in two eyes from either treatment group. Conjunctival edema was absent from all eyes in Group 1 at all times and noted in two eyes of Group 2 at the exit visit.

Corneal edema was absent in all patients from both groups at the day 15 exit visit. Minimal fluorescein staining of the cornea was seen in eight eyes from Group 1 and in three eyes from Group 2 by day 1 ; in six and nine eyes from Group 1 and 2, respectively, by day 3; and in four and six eyes, respectively, by day 15 . These differences between treatment groups were not statistically significant.

Table 6 lists the results of tolerability criteria for the drug formulations used in the study as subjectively reported by patients during interviews. On the first postoperative day, 18 eyes from either group were said to have moderate tearing, which subsided to mild tearing in four eyes from Group 1
Table 6 Ocular symptoms over time by treatment group $(\mathrm{N}=194)$

\begin{tabular}{|c|c|c|c|c|c|c|}
\hline \multirow[t]{2}{*}{$\begin{array}{l}\text { Patient-reported } \\
\text { symptom }\end{array}$} & \multirow[t]{2}{*}{ Dayc } & \multicolumn{2}{|c|}{$\begin{array}{l}\text { Group Ia } \\
n=100\end{array}$} & \multicolumn{2}{|c|}{$\begin{array}{l}\text { Group } 2^{b} \\
n=94\end{array}$} & \multirow[t]{2}{*}{$P$} \\
\hline & & No. & $\overline{(\%)}$ & No. & (\%) & \\
\hline \multirow[t]{4}{*}{ Tearing } & -2 & 2 & (2) & 0 & $(0)$ & 0.1692 \\
\hline & 1 & 18 & (18) & 18 & (19.1) & 0.8374 \\
\hline & 3 & 4 & (4) & 0 & $(0)$ & 0.0605 \\
\hline & 15 & 4 & (4) & 0 & $(0)$ & 0.0605 \\
\hline \multirow[t]{4}{*}{ Discomfort $^{d}$} & -2 & 2 & (2) & 0 & (0) & 0.1692 \\
\hline & 1 & 34 & (34) & 25 & (26.6) & 0.2638 \\
\hline & 3 & 24 & (24) & 11 & (II.7) & 0.0264 \\
\hline & 15 & 14 & (14) & 9 & $(9.6)$ & 0.3419 \\
\hline \multirow[t]{4}{*}{ Pain } & -2 & 0 & $(0)$ & 0 & $(0)$ & - \\
\hline & 1 & 7 & (7) & 8 & (8.5) & 0.6946 \\
\hline & 3 & 2 & $(2)$ & 0 & (0) & 0.1692 \\
\hline & 15 & 0 & (0) & 0 & (0) & - \\
\hline
\end{tabular}

Notes: aCombined treatment with gatifloxacin + prednisolone; ${ }^{b}$ Separate treatment with gatifloxacin and prednisolone; In relation to laser-assisted in situ keratomileusis; ${ }^{d}$ Foreign-body sensation, itching, or photophobia.

and no tearing in all eyes from Group 2 on subsequent day 3 and day 15 visits. Ocular discomfort, represented by foreignbody sensation, itching, or photophobia, was present in 34 and 25 eyes from the respective groups on day 1, and in 24 and 11 eyes on day 3 , respectively. The latter difference was statistically significant. By day 15 , discomfort persisted in 14 eyes from Group 1 and in nine eyes from Group 2.

As to ocular pain, it was rated minimal or mild in seven eyes from Group 1 and in eight eyes from Group 2 on the first postoperative day. On day 3 , only two eyes from Group 1 reported minimal pain and by day 15 it had disappeared altogether.

Dilated funduscopy showed normal vitreous, retina, macula, and choroid of all eyes at the day 15 exit visit. No adverse event related to the study medications was reported at any time.

\section{Discussion}

Despite the popularity of LASIK and its admirable safety record, the risk of infection, however small, is always present. Every effort should be made to avert an infectious process during any invasive procedure on the eye, but especially in an elective surgery like laser keratomileusis. That is the reason for the widespread use of prophylactic, wide-spectrum, topical antibiotics in this setting.

Early postoperative inflammation and problems with wound healing also contribute to adverse effects seen after LASIK. ${ }^{15}$ A not-infrequent complication of refractive surgery is diffuse lamellar keratitis (DLK) or sands of the Sahara syndrome. ${ }^{16-20}$ DLK is characterized by diffuse inflammation 
at the flap interface after lamellar corneal surgery, apparently of noninfectious origin. Moshirfar et $\mathrm{al}^{20}$ note a $2.66 \%$ incidence of post-LASIK keratitis, with DLK being the most common diagnosis overall. The occurrence of noninfectious keratitis $(2.34 \%)$ was 7.5 times greater than that of infectious keratitis $(0.31 \%) .{ }^{20}$ The mechanism for DLK after LASIK has been shown to be disruption of the epithelial barrier integrity at the flap margin. ${ }^{16}$ It is therefore of the utmost importance to control the burgeoning inflammatory reaction on the corneal surface that might lead to development of DLK; for this, steroids are typically prescribed. ${ }^{21-23}$ In addition to their prophylactic effect, early diagnosis and treatment with topical corticosteroids can achieve complete resolution without visual loss even in advanced cases of DLK. ${ }^{24,25}$

Combination eye drops consisting of an antibiotic plus an anti-inflammatory have proved valuable in ophthalmic surgery. The combined formulations simplify application, minimize dosing errors, prevent medication washout, increase patient compliance with the drug regimen, and lower the purchase cost to the patient. ${ }^{26-31}$ Clinical outcomes are also apparently improved by using combination products. This beneficial effect has been ascribed to greater drug efficacy achieved through better patient compliance and/or less washout. ${ }^{31}$

Various fluoroquinolone plus corticosteroid topical combinations have been proposed in recent years, and experimental as well as clinical studies of these products have shown overall superior results. ${ }^{32-35}$ Fourth-generation fluoroquinolones are the first choice for ophthalmic antimicrobial prophylaxis, ${ }^{11}$ and topical glucocorticoids such as prednisolone acetate and dexamethasone reliably control inflammatory reactions on the ocular surface. ${ }^{36-39}$ An earlier study by Campos et $\mathrm{al}^{40}$ evaluated the fixed-dose formulation of moxifloxacin plus dexamethasone for topical prophylaxis in LASIK and found it to be therapeutically equivalent to conventional dosing with the separate agents and well tolerated by patients.

The present study compared the relative efficacy and tolerability of two prophylactic drug regimens after LASIK: a combined $0.3 \%$ gatifloxacin $+1 \%$ prednisolone eye drop formulation and the same agents administered singly from separate bottles. No evidence of infection was detected in any eye at any time. Conjunctival hyperemia and minimal corneal staining were noted in the early postoperative period (day 1) in up to $8 \%$ of eyes from the combination drops group; these findings largely resolved within 2 weeks and were not statistically different from those recorded with the separate medications. Other objective signs of ocular surface inflammation were minimal and transient regardless of treatment.
LASIK, like all eye surgeries, involves controlled trauma to the ocular tissues followed by a period of recovery and healing. In this study, the subjective impression of ocular discomfort (foreign-body sensation, itching, or photophobia) was reported in more eyes from the combined gatifloxacin + prednisolone group than from the separate gatifloxacin and prednisolone group. By day 15, the sensation of discomfort persisted in 14 eyes from Group 1 and in nine eyes from Group 2, though it was ill-defined, minimal, and of no clinical or statistical significance. This finding remains unexplained except that it may reflect the cohorts' idiosyncrasies.

There were no adverse reactions related to either drug regimen, and all patients appeared to tolerate the eye drops very well.

\section{Conclusion}

A fixed-dose formulation of gatifloxacin + prednisolone was found to be effective and well tolerated for topical prophylaxis post-LASIK. The combined antibiotic plus anti-inflammatory eye drop suspension was therapeutically equivalent to conventional therapy with individual bottles of gatifloxacin and prednisolone in this population.

\section{Acknowledgment}

The authors wish to acknowledge Sandra Malagutti for the statistical analysis of the study data and Grace Darling for her medical writing contribution to this paper.

\section{Disclosure}

The authors have no financial interest in any of the products used in this study, which was supported in part by Allergan Produtos Farmacêuticos Ltda, São Paulo-SP, Brazil. The trademarks herein are the property of their respective owners.

\section{References}

1. Durrie D, Stahl J. A randomized clinical evaluation of the safety of Systane Lubricant Eye Drops for the relief of dry eye symptoms following LASIK refractive surgery. Clin Ophthalmol. 2008;2(4):973-979.

2. Salomao MQ, Ambrosio R Jr, Wilson SE. Dry eye associated with laser in situ keratomileusis: mechanical microkeratome versus femtosecond laser. J Cataract Refract Surg. 2009;35(10):1756-1760.

3. Abelson M, Protzko E, Shapiro A, et al. A randomized trial assessing the clinical efficacy and microbial eradication of $1 \%$ azithromycin ophthalmic solution vs tobramycin in adult and pediatric subjects with bacterial conjunctivitis. Clin Ophthalmol. 2007;1(2):177-182.

4. Sandoval HP, Fernandez de Castro LE, Vroman DT, Solomon KD. A review of the use of ketorolac tromethamine $0.4 \%$ in the treatment of post-surgical inflammation following cataract and refractive surgery. Clin Ophthalmol. 2007;1(4):367-371.

5. Cho H, Wolf KJ, Wolf EJ. Management of ocular inflammation and pain following cataract surgery: focus on bromfenac ophthalmic solution. Clin Ophthalmol. 2009;3:199-210.

6. Miller D. Review of moxifloxacin hydrochloride ophthalmic solution in the treatment of bacterial eye infections. Clin Ophthalmol. 2008;2(1):77-91. 
7. Bucci FA Jr, Amico LM, Evans RE. Antimicrobial efficacy of prophylactic gatifloxacin $0.3 \%$ and moxifloxacin $0.5 \%$ in patients undergoing phacoemulsification surgery. Eye Contact Lens. 2008;34(1):39-42.

8. Moshirfar M, Chew J, Werner L, et al. Comparison of the effects of fourthgeneration fluoroquinolones on corneal re-epithelialization in rabbit eyes. Graefes Arch Clin Exp Ophthalmol. 2008;246(10):1455-1461.

9. Williams KK, McCartney MD, Rice RL, et al. The effects of moxifloxacin ophthalmic solution $0.5 \%$ or gatifloxacin ophthalmic solution $0.3 \%$ treatment on corneal wound healing in pigmented rabbits following anterior keratectomy. Vet Ophthalmol. 2008;11(5):327-334.

10. Tsai TH, Chen WL, Hu FR. Comparison of fluoroquinolones: cytotoxicity on human corneal epithelial cells. Eye. 2010;24(5):909-917.

11. Scoper SV. Review of third- and fourth-generation fluoroquinolones in ophthalmology: in-vitro and in-vivo efficacy. Adv Ther. 2008;25(10):979-994.

12. Levine JM, Noecker RJ, Lane LC, et al. Comparative penetration of moxifloxacin and gatifloxacin in rabbit aqueous humor after topical dosing. J Cataract Refract Surg. 2004;30(10):2177-2182.

13. Donnenfeld RS, Perry HD, Solomon R, et al. A comparison of gatifloxacin to ciprofloxacin in the prophylaxis of Streptococcus pneumoniae in rabbits in a LASIK model. Eye Contact Lens. 2006;32(1):46-50.

14. Akram M, Shyum SB, Gauhar S. Development of new ophthalmic suspension prednisolone acetate 1\%. Pak J Pharm Sci. 2010;23(2): 149-154.

15. Alio JL, Perez-Santonja JJ, Tervo T, et al. Postoperative inflammation, mkicrobial complications, and wound healing following laser in situ keratomileusis. J Refract Surg. 2000;16(5):523-538.

16. Asano-Kato N, Toda I, Tsuruya T, et al. Diffuse lamellar keratitis and flap margin epithelial healing after laser in situ keratomileusis. J Refract Surg. 2003;19(1):30-33.

17. Buhren J, Kohnen T. Corneal wound healing after laser in situ keratomileusis flap lift and epithelial abrasion. J Cataract Refract Surg. 2003;29(10):2007-2012.

18. Jin GJ, Lyle WA, Merkley KH. Late-onset idiopathic diffuse lamellar keratitis after laser in situ keratomileusis. $J$ Cataract Refract Surg. 2005; 31(2):435-437.

19. Hadden OB, Patel D, Gray TB, et al. Multifocal lamellar keratitis following laser in situ keratomileusis. J Cataract Refract Surg. 2007; 33(1):144-147.

20. Moshirfar M, Welling JD, Feiz V, et al. Infectious and noninfectious keratitis after laser in situ keratomileusis: occurrence, management, and visual outcomes. J Cataract Refract Surg. 2007;33(3):474-483.

21. Sridhar MS, Rao SK, Vajpayee RB, et al. Complications of laser-insitu-keratomileusis. Indian J Ophthalmol. 2002;50(4):265-282.

22. Holzer MP, Sandoval HP, Vargas LG, et al. Corneal flap complications in refractive surgery: Part 2: postoperative treatment of diffuse lamellar keratitis in an experimental animal model. J Cataract Refract Surg. 2003;29(4):803-807.

23. Karimian F, Yurdkhani $\mathrm{H}$, Anisian A, et al. Topical steroids for prevention of diffuse lamellar keratitis following LASIK. Iran J Ophthalmic Res. 2007;2(2):119-123.

24. Shah MN, Misra M, Wihelmus KR, Koch DD. Diffuse lamellar keratitis associated with epithelial defects after laser in situ keratomileusis. J Cataract Refract Surg. 2000;26(9):1312-1318.

25. Ng EY, Thinagaran S, Kinsella F, O'Keefe M. Prophylaxis of diffuse lamellar keratitis with intraoperative interface steroids in LASIK. J Refract Surg. 2009;25(3):306-311.

Clinical Ophthalmology

\section{Publish your work in this journal}

Clinical Ophthalmology is an international, peer-reviewed journal covering all subspecialties within ophthalmology. Key topics include: Optometry; Visual science; Pharmacology and drug therapy in eye diseases; Basic Sciences; Primary and Secondary eye care; Patient Safety and Quality of Care Improvements. This journal is indexed on PubMed Submit your manuscript here: http://www.dovepress.com/clinical-ophthalmology-journal
26. Renard G, Adenis JP, Rouland JF, et al. Efficacy and tolerability of a combination of indomethacin and gentamicin for preventing inflammation after cataract surgery. J Fr Ophthalmol. 1996;19(11):689-695.

27. Van Endt JJ, Veraart HG, Kramer R, et al. A comparison of two ophthalmic steroid-antibiotic combinations after cataract surgery. Eur J Ophthalmol. 1997;7(2):144-148.

28. Shepherd WF, Fsadni MG, Raj PS; Diclofenac-gentamicin versus Gentamicin Study Group. A clinical evaluation of diclofenac-gentamicin combination eye drops in the control of inflammation after cataract surgery. Ocul Immunol Inflamm. 1998;6(1):13-18.

29. Barraquer RI, Alvarez de Toledo JP, Montane D, et al. Fixed-dose combination of $0.1 \%$ diclofenac plus $0.3 \%$ tobramycin ophthalmic solution for inflammation after cataract surgery: a randomized, comparative, active treatment-controlled trial. Eur J Ophthalmol. 1998;8(3):173-178.

30. Russo S, Papa V, Di Bella A, et al. Dexamethason-netilmicin: a new ophthalmic steroid-antibiotic combination. Efficacy and safety after cataract surgery. Eye. 2007;21(1):58-64.

31. Notivol R, Amin D, Whitling A, et al. Prophylactic effectiveness of tobramycin-dexamethasone eye drops compared with tobramycin/ vehicle eye drops in controlling post-surgical inflammation in cataract patients: prospective, randomised, double-masked, two-arm, parallelgroup, placebo-controlled, multicentre study. Clin Drug Invest. 2004; 24(9):523-533.

32. Freitas LL, Soriano E, Muccioli C, et al. Efficacy and tolerability of a combined moxifloxacin/dexamethasone formulation for topical prophylaxis and reduction of inflammation in phacoemulsification: a comparative, double masked clinical trial. Curr Med Res Opin. 2007; 23(12):3123-3130.

33. Gross RL, Sullivan EK, Wells DT, et al. Pooled results of two randomized clinical trials comparing the efficacy and safety of travoprost $0.004 \% /$ timolol $0.5 \%$ in fixed combination versus concomitant travoprost $0.004 \%$ and timolol $0.5 \%$. Clin Ophthalmol. 2007; 1(3):317-322.

34. Holland EJ, Bartlett JD, Paterno MR, et al. Effects of loteprednol/ tobramycin versus dexamethasone/tobramycin on intraocular pressure in healthy volunteers. Cornea. 2008;27(1):50-55.

35. Shin JH, Lee HB, Park HY. Comparison of the effects of fourthgeneration fluoroquinolones on epithelial healing after photorefractive keratectomy. Cornea. 2010;29(11):1236-1240.

36. Diestelhorst M, Aspacher F, Konen W, et al. Effect of dexamethasone $0.1 \%$ and prednisolone acetate $1.0 \%$ eye drops on the blood-aqueous barrier after cataract surgery: a controlled randomized fluorophotometric study. Graefes Arch Clin Exp Ophthalmol. 1992;230(5):451-453.

37. Ostrov CS, Sirkin SR, Deutsch WE, et al. Ketorolac, prednisolone, and dexamethasone for postoperative inflammation. Clin Ther. 1997; 19(2):259-272.

38. Simone JN, Pendelton RA, Jenkins JE. Comparison of the efficacy and safety of ketorolac tromethamine $0.5 \%$ and prednisolone acetate $1 \%$ after cataract surgery. J Cataract Refract Surg. 1999;25(5):699-704.

39. Struck HG, Bariszlovich A. Comparison of $0.1 \%$ dexamethasone phosphate eye gel (Dexagel) and 1\% prednisolone acetate eye suspension in the treatment of post-operative inflammation after cataract surgery. Graefes Arch Clin Exp Ophthalmol. 2001;239(10):737-742.

40. Campos M, Avila M, Wallau A, et al. Efficacy and tolerability of a fixed-dose moxifloxacin-dexamethasone formulation for topical prophylaxis in LASIK: a comparative, double-masked clinical trial. Clin Ophthalmol. 2008;2(2):331-338.

\section{Dovepress}

Central and CAS, and is the official journal of The Society of Clinical Ophthalmology (SCO). The manuscript management system is completely online and includes a very quick and fair peer-review system, which is all easy to use. Visit http://www.dovepress.com/testimonials. php to read real quotes from published authors. 